\title{
The Number of Adverse Childhood Experiences Is Associated with Emotional and Behavioral Problems among Adolescents
}

\author{
Miriama Lackova Rebicova ${ }^{1,2, *}$, Zuzana Dankulincova Veselska ${ }^{1,2}$, Daniela Husarova ${ }^{1,2}$, \\ Andrea Madarasova Geckova ${ }^{1,2,3}$, Jitse P. van Dijk ${ }^{2,3,4}$ and Sijmen A. Reijneveld ${ }^{4}$ \\ 1 Department of Health Psychology, Medical Faculty, Pavol Jozef Safarik University, Trieda SNP 1, \\ 04011 Kosice, Slovakia \\ 2 Graduate School Kosice Institute for Society and Health, Pavol Jozef Safarik University, Trieda SNP 1, \\ 04011 Kosice, Slovakia \\ 3 Olomouc University Social Health Institute, Palacky University in Olomouc, Univerzitni 22, 77111 Olomouc, \\ Czech Republic \\ 4 Department of Community \& Occupational Health, University Medical Center Groningen, University of \\ Groningen, Antonius Deusinglaan 1, 9713 AV Groningen, The Netherlands \\ * Correspondence: miriama.rebicova@upjs.sk; Tel.: +421-055-234-3263
}

Received: 30 May 2019; Accepted: 5 July 2019; Published: 9 July 2019

\begin{abstract}
This study aims to examine the association of adverse childhood experiences (ACE) with emotional and behavioral problems (EBP) among adolescents and the degree to which this association is stronger for more ACE. In addition, we assessed whether socioeconomic position (SEP) modifies the association of ACE with EBP. We obtained data from 341 adolescents aged 10-16 (mean age $=13.14$ years; $44.0 \%$ boys), the baseline of a cohort study. We measured EBP with the strengths and difficulties questionnaire and socioeconomic position (SEP) with self-reported financial status. We used generalized linear models to analyze the association between ACE (0 vs. $1-2$ vs. 3 and more) and EBP, and the modifying effect of SEP. Adolescents with 1-2 ACE (regression coefficient: 0.19; 95\%-confidence interval (CI): 0.06-0.32) and with 3 ACE and over (0.35; 0.17-0.54) reported more overall problems compared with adolescents without ACE. Moreover, adolescents with 1-2 ACE $(0.16 ;-0.01-0.32$, and $0.16 ; 0.03-0.29)$ and with 3 and over ACE $(0.33 ; 0.10-0.56$, and $0.28 ; 0.09-0.47)$ reported more emotional problems and behavioral problems, respectively. The interactions of SEP with ACE were not significant. ACE are related to EBP among adolescents, with a clear dose-response association, and this association similarly holds for all SEP categories.
\end{abstract}

Keywords: adverse childhood experiences; emotional problems; behavioral problems; adolescence

\section{Introduction}

Adverse childhood experiences (ACE) relate to various negative experiences at young ages; these include abuse and/or neglect towards a child, domestic violence towards the youth's mother, household substance abuse, household mental illness, parental separation/divorce, and a household member with a history of jail/imprisonment [1]. Their prevalence is high, e.g., Bellis et al. [2] found a lifetime cumulative prevalence of at least one ACE of 50\%. Stressors such as abuse, neglect, and witnessing domestic violence are similarly common during childhood [3-5]. ACE can lead to signs of depression, anxiety, and personality disorder [3,6-9], showing childhood ACE to be a major public health challenge.

The experience of long-term ACE can cause serious emotional and behavioral problems (EBP) throughout the life of an individual. A dose-response has been found of ACE with various conditions, including depression, anxiety, panic reactions, hallucinations, psychosis, and suicide attempt, along 
with overall psychopathology, psychotropic medication use, and treatment for mental disorders. The mechanisms for these associations may involve differences in the physiological development of children or by adopting behaviors that harm their physical and mental health [6,10]. However, most of the available evidence has focused on the impact of ACE on adult health [11,12]. A recent study shows that the exposure to multiple types of ACE is associated with a higher prevalence of psychiatric disorders in adults [11]. ACE may also be expected to have effects still in adolescence [13], but evidence to support this is lacking.

Low socioeconomic position might be considered as one of the ACE itself and to a great extent causes early life stress $[14,15]$. It is noteworthy that experienced financial stress was found to be associated with developing mental health [16] and behavioral problems [17]. However, the role of the socioeconomic position in the relationship between ACE and EBP is still unclear.

Therefore, the aim of this study is to examine the association of adverse childhood experiences (ACE) with emotional and behavioral problems (EBP) among adolescents and the degree to which this association is stronger for more ACE. In addition, we assessed whether socioeconomic position modifies the association of ACE with EBP.

\section{Materials and Methods}

\subsection{Sample and Procedure}

We used data from the baseline wave of the Care4Youth-cohort study. We obtained participants using a two-step sampling. First, we randomly selected primary schools; these were approached from January to June 2017. Out of 11 primary schools approached, seven participated in our survey (response rate $64 \%$ ). Next, parents of all pupils were asked to provide us with a signed informed consent on behalf of their children and themselves (response rate 23.4\%). Questionnaires were administered by trained research assistants in the absence of teachers during regular class time. We obtained data from 341 adolescents from 5th to 9th grade aged from 10 to 16 (response rate: 94.3\%, mean age: 13.14; boys: $44.0 \%$ ). The study protocol was approved by the Ethics Committee of the Medical Faculty at P. J. Safarik University in Kosice (2N/2015).

\subsection{Measures}

Emotional and behavioural problems (EBP) were measured with the strengths and difficulties questionnaire (SDQ), which includes 25 items [18], of which we used the 20 difficulty items. Response categories were: not true (0), somewhat true (1), certainly true (2). The resulting score for overall difficulties can range from $0-40$. In addition, we computed emotional problems (score 0-20, emotional symptoms and peer relationship problems subscales) and behavioral problems (score 0-20, conduct problems and hyperactivity/inattention subscales) [19]. A higher score indicates more problems in adolescents. Cronbach's alpha for the whole scale was 0.78 in our sample and 0.73 and 0.71 for the internalizing and externalizing subscales, respectively.

Adverse childhood experiences were measured by the question: "Have you ever experienced any of the following serious events? (Death of a brother/sister, Death of your father/mother, Death of somebody else you love, Long or serious illness of yourself, Long or serious illness of one of your parents or of someone else close to you, Problems of one of your parents with alcohol or drugs, Repeated serious conflicts or physical fights between your parents, Separation/divorce of your parents, Separation of your parents due to work abroad). The response categories were "Yes" and "No". We created a sum score for the number of ACE experienced, with a higher score indicating more ACE. Consequently, we categorized the number of ACE into three categories: no ACE (0), one or two ACE (1), and three or more ACE (2).

Socioeconomic position (SEP) [20] was measured using a validated tool among adolescents [21] on a 10-point scale ( 0 - the worst, 10-the best), and the adolescents were asked to assess where they see their families on this ladder according to their financial status [22]. To illustrate what is meant, a 
description was provided e.g., about how much money the family had, what level of education their parents had achieved, and how profitable the work of their parents is.

\subsection{Statistical Analyses}

We first described the background characteristics of the sample, overall and by gender. Next, we assessed the association of ACE with EBP using generalized linear models adjusted for age and gender with ACE in three categories. Finally, we assessed modification of this association by the family's SEP. Statistical analyses were performed using IBM SPSS Statistics v.20 IBM Corpotation (New York, NY, USA) for Windows.

\section{Results}

\subsection{Descriptive Statistics}

Table 1 shows the descriptive statistics of the EBP and ACE for the whole study sample and by boys and girls separately.

Table 1. Descriptive statistics for age, socioeconomic position, emotional and behavioral problems, and adverse childhood experiences, overall and by gender (Slovakia 2017, 10-16 years old, $n=341$ ).

\begin{tabular}{cccc}
\hline & Whole Sample $(\boldsymbol{n}=\mathbf{3 4 1})$ & Boys $(\boldsymbol{n}=\mathbf{1 5 0})$ & Girls $(\boldsymbol{n}=\mathbf{1 9 1})$ \\
\hline Age (mean, SD) & $13.14 ; 1.43$ & $13.18 ; 1.43$ & $13.11 ; 1.44$ \\
Socioeconomic position (mean, SD) & $7.15 ; 1.56$ & $7.21 ; 1.51$ & $7.10 ; 1.60$ \\
EBP (mean, SD) & & & \\
Overall difficulties & $11.71 ; 5.74$ & $10.89 ; 5.62$ & $12.36 ; 5.77$ \\
Emotional problems & $5.07 ; 3.51$ & $4.10 ; 3.09$ & $5.83 ; 3.63$ \\
Behavioral problems & $6.65 ; 3.43$ & $6.88 ; 3.64$ & $6.47 ; 3.25$ \\
ACE ( $n, \%)$ & & & \\
No ACE & $101 ; 31.0$ & $44 ; 30.8$ & $57 ; 31.1$ \\
1-2 ACE & $178 ; 54.6$ & $86 ; 60.1$ & $92 ; 50.3$ \\
3 and more ACE & $47 ; 14.4$ & $13 ; 9.1$ & $34 ; 18.6$ \\
\hline
\end{tabular}

SD—standard deviation; ACE—adverse childhood experiences; EBP—emotional and behavioral problems; $n-$ number of respondents.

\subsection{Associations between the Number of ACE and Emotional and Behavioral Problems}

Table 2 presents regression coefficients (B) and 95\%-confidence intervals (CI) from the generalized linear models adjusted for age and gender. Model 1 shows that adolescents with 1-2 ACE (B: 0.19; 95\% CI: $0.06-0.32)$ and 3 or more ACE $(0.35 ; 0.17-0.54)$ reported more overall difficulties in comparison with adolescents without ACE. When separately assessing emotional and behavioral problems, a similar dose-response was found with somewhat lower B coefficients. In Model 2, adolescents with a higher socioeconomic position reported fewer overall emotional $(-0.05 ;-0.09-(-0.02))$ and fewer behavioral problems $(-0.05 ;-0.09-(-0.01))$. However, the interactions of SEP with ACE were not significant (not shown in the table). 
Table 2. Associations between the number of adverse childhood experiences (ACE) and emotional and behavioral problems, overall and separately adjusted for gender, age (Model 1), and socioeconomic position (Model 2) from generalized linear models (B coefficients/95\% Wald confidence intervals) (Slovakia 2017, 10-16 years old, $n=341)$.

\begin{tabular}{|c|c|c|c|c|c|c|}
\hline & \multicolumn{2}{|c|}{ Overall Difficulties } & \multicolumn{2}{|c|}{ Emotional Problems } & \multicolumn{2}{|c|}{ Behavioral Problems } \\
\hline & $\begin{array}{c}\text { Model 1 } \\
\text { B }(95 \% \text { CI })\end{array}$ & $\begin{array}{c}\text { Model 2 } \\
\text { B }(95 \% \text { CI })\end{array}$ & $\begin{array}{c}\text { Model 1 } \\
\text { B }(95 \% \text { CI })\end{array}$ & $\begin{array}{c}\text { Model 2 } \\
\text { B }(95 \% \text { CI })\end{array}$ & $\begin{array}{c}\text { Model 1 } \\
\text { B }(95 \% \text { CI })\end{array}$ & $\begin{array}{c}\text { Model } 2 \\
\text { B }(95 \% \text { CI })\end{array}$ \\
\hline \multicolumn{7}{|l|}{$\mathrm{ACE}$} \\
\hline 0 & Ref. & Ref. & Ref. & Ref. & Ref. & Ref. \\
\hline $1-2$ & $0.19(0.06-0.32)^{* *}$ & $0.18(0.06-0.31)^{* *}$ & $0.16(-0.01-0.32)$ & $0.15(-0.01-0.31)$ & $0.16(0.03-0.29) *$ & $0.15(0.02-0.28) *$ \\
\hline 3 and more & $0.35(0.17-0.54) * * *$ & $0.30(0.12-0.49) * *$ & $0.33(0.10-0.56) * *$ & $0.28(0.05-0.51)$ * & $0.28(0.09-0.47)^{* *}$ & $0.23(0.05-0.42) *$ \\
\hline \multicolumn{7}{|l|}{ Gender } \\
\hline Boys & Ref. & Ref. & Ref. & Ref. & Ref. & Ref. \\
\hline Girls & $0.12(0.00-0.23) *$ & $0.11(0.00-0.23) *$ & $0.31(0.17-0.46)^{* * *}$ & $0.32(0.17-0.46)^{* * *}$ & $-0.08(-0.19-0.04)$ & $-0.08(-0.19-0.04)$ \\
\hline Age & $0.04(0.00-0.08) *$ & $0.03(-0.01-0.07)$ & $0.03(-0.02-0.08)$ & $0.02(-0.03-0.07)$ & $0.05(0.00-0.09) *$ & $0.04(-0.00-0.08)$ \\
\hline Socioeconomic position $(0-10)$ & & $-0.05(-0.09-(-0.02))^{* * *}$ & & $-0.04(-0.09-0.00)$ & & $-0.05(-0.09-(-0.01)) *$ \\
\hline Pseudo $\mathrm{R}^{2}$ & 0.0787 & 0.1048 & 0.0843 & 0.096 & 0.0505 & 0.0679 \\
\hline
\end{tabular}




\section{Discussion}

The present study shows that ACE are associated with EBP and that the accumulation of ACE is associated with more EBP. Socioeconomic position does not significantly influence the relationship between ACE and EBP.

As suggested by our results, more ACE seems to be associated with more EBP among adolescents, thus adding to the already existing evidence on adults $[6,8,9,12]$. Experience of traumatic events in childhood might represent high levels of distress, which might be associated with emotional or behavioral problems [23] via enduring changes in the nervous systems [6,17,24]. In addition, it might be expected that the mentioned ACE from childhood are still present even in adolescence and have a direct and immediate influence. The deleterious effects of ACE on mental health may thus already start in adolescence.

We found the association between ACE and EBP to have a clear dose-response association, with more ACE having more pronounced influence, in line with Chapman et al. [25]. An explanation for the dose-response character of the association might be found in the resilience theory [26-29], suggesting that a lower number of ACE might be buffered by existing resilience factors, whether within the individual, family, or community [30,31]. Several simultaneously present ACE, however, might often not be resolvable by the available resources. This might lead to more EBP, thus requiring additional help from professionals from the adolescent mental health care system more frequently.

Contrary to our expectations, we found no influence of adolescents' perceived SEP on the association between ACE and EBP. Most such studies have examined the association of SEP with ACE $[9,32]$ or with the development of EBP [13]. Evidence on the role of SEP between ACE and EBP is scarce and inconclusive and mostly in adult populations [32,33]; our study provides additional evidence on this understudied issue. An explanation for there being no influence of adolescents' perceived SEP on the association between ACE and EBP may be the fact that in comparison with experiencing other multiple adverse experiences in the presence of traumatic events, lower SEP might not be considered as an additional burden leading to even more pronounced EBP [34]. On the contrary, lower SEP might be expected to result in more ACE, which in turn have a detrimental influence on the development of EBP among adolescents, thus suggesting a different pathway.

This study has several strengths, the most important being that it uses validated internationally recognized instruments that have been used in various studies [35-37]. In addition, our study contributes to the current literature by investigating the interaction between ACE and EBP on mental health in a community-based sample of adolescents. However, this study also has some limitations. First, its response rate was rather low due to required active parental consent. However, we do not expect this to cause a major selection bias, e.g., Dent et al. [38] found no differences in mental health outcomes from studies with active and passive parental consent. Another limitation might be use of self-reported data for measuring SEP, ACE, and EBP. However, previous research has confirmed the validity of self-reported measurement of SEP [21], EBP [18], and ACE [37,39]. Finally, the cross-sectional design of this study made it impossible to formulate conclusive statements about causality.

Our study showed that ACE are associated with EBP among adolescents, with more ACE having a stronger association with EBP. These results imply a need to focus on prevention and early identification of adolescents exposed to ACE. Based on our results, implications for further research might be of interest for investigating individual ACE, as well as differentiating by the severity of the ACE. Furthermore, we in particular need longitudinal studies to assess pathways and existing mechanisms regarding the associations of socioeconomic position of the family, ACE, and EBP. Finally, research is needed on intervening in the chain of ACE towards EBP, to be able to improve future adolescent and adult mental health.

\section{Conclusions}

We found that ACE are related to EBP among adolescents and that an increasing number of ACE is associated with more EBP; SEP did not modify this association. Our results provide further evidence 
of associations between ACE and EBP and underscore the need for a public health and social welfare approach regarding prevention, risk reduction, and early intervention for adolescents exposed to ACE.

Author Contributions: Conceptualization: M.L.R, Z.D.V. and A.M.G.; Data Curation: M.L.R., Z.D.V. and D.H.; Formal Analysis: M.L.R., Z.D.V., D.H., A.M.G. and S.A.R.; writing-original draft preparation: M.L.R.; Methodology: Z.D.V.; Supervision: Z.D.V., D.H., A.M.G., J.P.v.D. and S.A.R.

Funding: This work was supported by the Research and Development Support Agency under Contract No. APVV-15-0012, and by the Scientific Grant Agency of the Ministry of Education, Science, Research and Sport of the Slovak Republic and the Slovak Academy of Sciences, Reg. No. 1/0981/15.

Conflicts of Interest: The authors declare no conflict of interest.

\section{References}

1. DeLisi, M.; Alcala, J.; Kusow, A.; Hochstetler, A.; Heirigs, M.H.; Caudill, J.W.; Trulson, C.R.; Baglivio, M.T. Adverse childhood experiences, commitment offense, and race/ethnicity: Are the effects crime-, race-, and ethnicity-specific? Int. J. Environ. Res. Public Health 2017, 14, 331. [CrossRef] [PubMed]

2. Bellis, M.A.; Hughes, K.; Leckenby, N.; Hardcastle, K.A.; Perkins, C.; Lowey, H. Measuring mortality and the burden of adult disease associated with adverse childhood experiences in England: A national survey. J. Public Health 2014, 37, 445-454. [CrossRef] [PubMed]

3. Connolly, E.J.; Kavish, N. The causal relationship between childhood adversity and developmental trajectories of delinquency: A consideration of genetic and environmental confounds. J. Youth Adolesc. 2019, 48, $199-211$. [CrossRef] [PubMed]

4. Anda, R.F.; Butchart, A.; Felitti, V.J.; Brown, D.W. Building a framework for global surveillance of the public health implications of adverse childhood experiences. Am. J. Prev. Med. 2010, 39, 93-98. [CrossRef] [PubMed]

5. Dong, M.; Anda, R.F.; Felitti, V.J.; Dube, S.R.; Williamson, D.F.; Thompson, T.J.; Loo, C.M.; Giles, W.H. The interrelatedness of multiple forms of childhood abuse, neglect, and household dysfunction. Child Abus. Negl. 2004, 28, 771-784. [CrossRef] [PubMed]

6. Danese, A.; McEwen, B.S. Adverse childhood experiences, allostasis, allostatic load, and age-related disease. Physiol. Behav. 2012, 106, 29-39. [CrossRef] [PubMed]

7. Kim, B.N.; Park, S.; Park, M.H. The relationship of sexual abuse with self-esteem, depression, and problematic internet use in Korean adolescents. Psychiatry Investig. 2017, 14, 372. [CrossRef] [PubMed]

8. Sala, M.; Caverzasi, E.; Lazzaretti, M.; Morandotti, N.; De Vidovich, G.; Marraffini, E.; Gambini, F.; Isola, M.; De Bona, M.; Rambaldelli, G.; et al. Dorsolateral prefrontal cortex and hippocampus sustain impulsivity and aggressiveness in borderline personality disorder. J. Affect. Disord. 2011, 131, 417-421. [CrossRef]

9. Cohen, R.A.; Grieve, S.; Hoth, K.F.; Paul, R.H.; Sweet, L.; Tate, D.; Gunstad, J.; Stroud, L.; McCaffery, J.; Hitsman, B.; et al. Early life stress and morphometry of the adult anterior cingulate cortex and caudate nuclei. Biol. Psychiatry 2006, 59, 975-982. [CrossRef]

10. Pechtel, P.; Pizzagalli, D.A. Effects of early life stress on cognitive and affective function: An integrated review of human literature. Psychopharmacology 2011, 214, 55-70. [CrossRef]

11. Park, S.; Hong, J.P.; Bae, J.N.; Cho, S.J.; Lee, D.W.; Lee, J.Y.; Chang, S.M.; Jeon, H.J.; Hahm, B.J.; Lee, Y.M.; et al. Impact of childhood exposure to psychological trauma on the risk of psychiatric disorders and somatic discomfort: Single vs. multiple types of psychological trauma. Psychiatry Res. 2014, 219, 443-449. [CrossRef] [PubMed]

12. Felitti, V.J.; Anda, R.F.; Nordenberg, D.; Williamson, D.F.; Spitz, A.M.; Edwards, V.; Marks, J.S. Relationship of childhood abuse and household dysfunction to many of the leading causes of death in adults: The Adverse Childhood Experiences (ACE) Study. Am. J. Prev. Med. 1998, 14, 245-258. [CrossRef]

13. Finkelhor, D.; Shattuck, A.; Turner, H.; Hamby, S. A revised inventory of adverse childhood experiences. Child Abus. Negl. 2015, 48, 13-21. [CrossRef] [PubMed]

14. Su, S.; Wang, X.; Pollock, J.S.; Treiber, F.A.; Xu, X.; Snieder, H.; McCall, W.V.; Stefanek, M.; Harshfield, G.A. Adverse childhood experiences and blood pressure trajectories from childhood to young adulthood: The Georgia stress and Heart study. Circulation 2015, 131, 1674-1681. [CrossRef] [PubMed]

15. Danese, A.; Moffitt, T.E.; Harrington, H.; Milne, B.J.; Polanczyk, G.; Pariante, C.M.; Poulton, R.; Caspi, A. Adverse childhood experiences and adult risk factors for age-related disease: Depression, inflammation, and clustering of metabolic risk markers. Arch. Pediatr. Adolesc. Med. 2009, 163, 1135-1143. [CrossRef] 
16. Noble, K.G.; Houston, S.M.; Kan, E.; Sowell, E.R. Neural correlates of socioeconomic status in the developing human brain. Dev. Sci. 2012, 15, 516-527. [CrossRef]

17. Hanson, J.L.; Nacewicz, B.M.; Sutterer, M.J.; Cayo, A.A.; Schaefer, S.M.; Rudolph, K.D.; Shirtcliff, E.A.; Pollak, S.D.; Davidson, R.J. Behavioral problems after early life stress: Contributions of the hippocampus and amygdala. Biol. Psychiatry 2015, 77, 314-323. [CrossRef] [PubMed]

18. Goodman, R.; Meltzer, H.; Bailey, V. The Strengths and Difficulties Questionnaire: A pilot study on the validity of the self-report version. Eur. Child Adolesc. Psychiatry 1998, 7, 125-130. [CrossRef] [PubMed]

19. Goodman, A.; Lamping, D.L.; Ploubidis, G.B. When to use broader internalising and externalising subscales instead of the hypothesised five subscales on the Strengths and Difficulties Questionnaire (SDQ): Data from British parents, teachers and children. J. Abnorm. Child Psychol. 2010, 38, 1179-1191. [CrossRef] [PubMed]

20. Viner, R.M.; Ozer, E.M.; Denny, S.; Marmot, M.; Resnick, M.; Fatusi, A.; Currie, C. Adolescence and the social determinants of health. Lancet 2012, 379, 1641-1652. [CrossRef]

21. Ekehammar, B.; Sidanius, J.; Nilsson, I. Social status: Construct and external validity. J. Soc. Psychol. 1987, 127, 473-481. [CrossRef]

22. Adler, N.E.; Epel, E.S.; Castellazzo, G.; Ickovics, J.R. Relationship of subjective and objective social status with psychological and physiological functioning: Preliminary data in healthy, White women. Health Psychol. 2000, 19, 586. [CrossRef] [PubMed]

23. Breslau, N.; Lucia, V.C.; Alvarado, G.F. Intelligence and other predisposing factors in exposure to trauma and posttraumatic stress disorder: A follow-up study at age 17 years. Arch. Gen. Psychiatry 2006, 63, 1238-1245. [CrossRef] [PubMed]

24. Anda, R.F.; Felitti, V.J.; Bremner, J.D.; Walker, J.D.; Whitfield, C.H.; Perry, B.D.; Dube, S.R.; Giles, W.H. The enduring effects of abuse and related adverse experiences in childhood. Eur. Arch. Psychiatry Clin. Neurosci. 2006, 256, 174-186. [CrossRef] [PubMed]

25. Chapman, D.P.; Whitfield, C.L.; Felitti, V.J.; Dube, S.R.; Edwards, V.J.; Anda, R.F. Adverse childhood experiences and the risk of depressive disorders in adulthood. J. Affect. Disord. 2004, 82, 217-225. [CrossRef] [PubMed]

26. Rutter, M. Resilience in the face of adversity: Protective factors and resistance to psychiatric disorder. Br. J. Psychiatry 1985, 147, 598-611. [CrossRef] [PubMed]

27. Rutter, M. Resilience concepts and findings: Implications for family therapy. J. Fam. Ther. 1999, $21,119-144$. [CrossRef]

28. Kim-Cohen, J. Resilience and developmental psychopathology. Child Adolesc. Psychiatr. Clin. N. Am. 2007, 16, 271-283. [CrossRef]

29. Ungar, M. Contextual and cultural aspects of resilience in child welfare settings. In Putting a Human Face on Child Welfare: Voices from the Prairies; University of Regina, Prairie Child Welfare Consortium: Edmonton, AB, Canada, 2007; pp. 1-23.

30. Garmezy, N. Resiliency and vulnerability to adverse developmental outcomes associated with poverty. Am. Behav. Sci. 1991, 34, 416-430. [CrossRef]

31. Werner, E.E. Resilience in development. Curr. Dir. Psychol. Sci. 1995, 4, 81-84. [CrossRef]

32. Wade, R., Jr.; Cronholm, P.F.; Fein, J.A.; Forke, C.M.; Davis, M.B.; Harkins-Schwarz, M.; Pachter, L.M.; Bair-Merritt, M.H. Household and community-level adverse childhood experiences and adult health outcomes in a diverse urban population. Child Abus. Negl. 2016, 52, 135-145. [CrossRef] [PubMed]

33. Björkenstam, E.; Hjern, A.; Mittendorfer-Rutz, E.; Vinnerljung, B.; Hallqvist, J.; Ljung, R. Multi-exposure and clustering of adverse childhood experiences, socioeconomic differences and psychotropic medication in young adults. PLoS ONE 2013, 8, e53551. [CrossRef] [PubMed]

34. Amone-P'Olak, K.; Burger, H.; Ormel, J.; Huisman, M.; Verhulst, F.C.; Oldehinkel, A.J. Socioeconomic position and mental health problems in pre-and early-adolescents. Soc. Psychiatry Psychiatr. Epidemiol. 2009, 44, 231-238. [CrossRef] [PubMed]

35. Bøe, T.; Hysing, M.; Skogen, J.C.; Breivik, K. The Strengths and Difficulties Questionnaire (SDQ): Factor structure and gender equivalence in Norwegian adolescents. PLoS ONE 2016, 11, e0152202. [CrossRef] [PubMed]

36. He, J.P.; Burstein, M.; Schmitz, A.; Merikangas, K.R. The Strengths and Difficulties Questionnaire (SDQ): The factor structure and scale validation in US adolescents. J. Abnorm. Child Psychol. 2013, 41, 583-595. [CrossRef] [PubMed] 
37. Muris, P.; Meesters, C.; van den Berg, F. The strengths and difficulties questionnaire (SDQ). Eur. Child Adolesc. Psychiatry 2003, 12, 1-8. [CrossRef] [PubMed]

38. Dent, C.W.; Sussman, S.Y.; Stacy, A.W. The impact of a written parental consent policy on estimates from a school-based drug use survey. Eval. Rev. 1997, 21, 698-712. [CrossRef]

39. Meinck, F.; Cosma, A.P.; Mikton, C.; Baban, A. Psychometric properties of the Adverse Childhood Experiences Abuse Short Form (ACE-ASF) among Romanian high school students. Child Abus. Negl. 2017, 72, 326-337. [CrossRef]

(C) 2019 by the authors. Licensee MDPI, Basel, Switzerland. This article is an open access article distributed under the terms and conditions of the Creative Commons Attribution (CC BY) license (http://creativecommons.org/licenses/by/4.0/). 